\title{
Factors Associated with Nursing Students' Intention to Report Needlestick Injuries: Applying the Theory of Planned Behavior
}

\author{
Nelson A. Ditching ${ }^{1}$, Angel Grace F. Furatero ${ }^{1}$, Razilee Vania S. Iquiña ${ }^{1}$, Aira Darlyn \\ M. Sabulao ${ }^{1}$, Jason M. Supremo ${ }^{1}$, Ryan Michael F. Oducado ${ }^{1}$ \\ ${ }^{1}$ College of Nursing, West Visayas State University, Philippines \\ Corresponding Author: Ryan Michael F. Oducado (rmoducado@wvsu.edu.ph)
}

Received: 3 July 2020

Revised: 26 September 2020

Accepted: 5 October 2020

\begin{abstract}
Background: Nursing students, like other healthcare workers, are prone to needlestick injuries. Over the years, studies have been conducted regarding needlestick injuries. However, its prevalence among Filipino nursing students' is still not known. Also, nursing students' intention to report needlestick injuries in the Philippines has not been explored.

Purpose: The purpose of this research was to determine the factors associated with the intention to report needlestick injuries among nursing students applying the Theory of Planned Behavior.

Methods: This cross-sectional study used the Needlestick Injuries Reporting Intention Scale (NIRIS) and was distributed among 233 senior nursing students in Iloilo City, Philippines. Descriptive statistics and Pearson's correlation were utilized to analyze the data.

Results: The results of the study revealed that $15 \%$ of nursing students had experienced a needlestick injury. However, only less than half $(45.71 \%)$ of those who sustained needlestick injury reported the incident. Nursing students exhibited a positive attitude $(M=5.41 ; S D=0.63)$ toward reporting needlestick injuries. They perceived a high social pressure $(M=4.65 ; S D=0.46)$, high behavioral control $(M=4.19 ; S D=0.45)$, and high intention $(M=8.99 ; S D=1.15)$ in reporting needlestick injuries. Attitude $(p=0.000)$, subjective norm $(p=0.000)$, and perceived behavioral control $(p=0.000)$ were significantly correlated with the intention to report needlestick injuries.

Conclusion: This study supports the Theory of Planned Behavior in identifying factors influencing nursing students' intention to report needlestick injuries.
\end{abstract}

Keywords: Needlestick injuries; nursing students; prevalence; Theory of Planned Behavior

How to Cite: Ditching, N. A., Furatero, A. G. F., Iquiña, R. V. S., Sabulao, A. D. M., Supremo, J. M., \& Oducado, R. M. F. (2020). Factors associated with nursing students' intention to report needlestick injuries: Applying the theory of planned behavior. Nurse Media Journal of Nursing, 10(3), 234-243. doi:10.14710/nmjn.v10i3.31975

Permalink/DOI: https://doi.org/10.14710/nmjn.v10i3.31975 


\section{BACKGROUND}

Needlestick injuries commonly occur in healthcare settings and can be serious (King \& Strony, 2020). According to World Health Organization, two million healthcare workers globally suffer from needlestick injuries yearly, causing the transmission of hepatitis B and C and Human Immunodeficiency Virus (HIV)/AIDS (Pavithran et al., 2015). The estimated global burden of diseases from occupational exposure to hepatitis B and $\mathrm{C}$ and HIV infections among healthcare workers reaches 39\%, 37\%, and 4.4\%, respectively (AlDakhil, Yenugadhati, Al-Seraihi, \& Al-Zoughool, 2019). Correspondingly, according to the Centers for Disease Control and Prevention report, the global estimates of needlestick injuries occurring each year is around 600,000 to one million (Tayaben, 2015). In the Philippines, available data on needlestick injuries in 2004 revealed a total of 4,004 healthcare workers reported to have acquired needlestick injuries (Padilla, Rogado, Tagalog, \& America, 2006).

The transmission of blood-borne pathogens poses an occupational hazard to healthcare workers. Despite awareness and guidelines on universal precaution, needlestick injuries continue to occur, and many go unreported (King \& Strony, 2020). Sharp injuries continue to be a primary concern among nurses (Tayaben, 2015). Unreported needlestick injuries also remain a concern among nursing students. This is because nursing students also perform procedures that involve needles and sharps during their clinical placements. A study reported that among healthcare groups, nursing students were the most vulnerable cohort for needlesticks injuries in a teaching hospital (Hada et al., 2018). Because of their not well-honed skills and limited clinical experiences, nursing students are less skillful when handling sharps thus are at greater risk of injury (Thomas, 2020). A review study demonstrated high rates of needlestick injuries among nursing students in low, middle, to even high-income countries (Handiyani, Kurniawidjaja, Irawaty, \& Damayanti, 2018). Aside from the alarmingly high rates of needlestick injuries, there is also a disturbingly low level of reporting the injury (Thomas, 2020). A study also disclosed poor correct practice of prevention of needlestick and sharps injuries among students (Quynh \& Einhellig, 2017).

Meanwhile, the Theory of Planned Behavior provides a theoretical backbone to study the correlates of nursing students' intention to report needlestick injuries. According to the Theory of Planned Behavior, intention to perform the behavior is determined by attitude, subjective norms, and perceived behavioral control (Ajzen, 1991). Many studies regarding health-related behaviors have tested the Theory of Planned Behavior (e.g., Gabriel, Hoch, \& Cramer, 2019; Hatefnia, Alizadeh, \& Ghorbani, 2019). Among samples of nurses and nursing students, the Theory of Planned Behavior has been tested on the intention to report medication errors (Natan, Sharon, Mahajna, \& Mahajna, 2017), child abuse (Atencion et al., 2019; Cho \& Kim, 2016) and adverse events (Ekayani, Wardhani, \& Rachmi, 2017).

Understanding the factors associated with reporting needlestick injuries is crucial in order to properly design interventions that foster the reporting of errors (Natan et al., 2017). The prevalence of needlestick injuries among Filipino nursing students is not known. There is an equal lack of research regarding nursing students' intention to report needlestick injuries in the Philippines setting. In addition, previous scholars have not 
examined whether constructs of the Theory of Planned Behavior are linked with reporting intention related to needlestick injuries. These were explored in this study.

\section{PURPOSE}

This study aimed to determine the factors associated with nursing students' intention to report needlestick injuries using the constructs of the Theory of Planned Behavior.

\section{METHODS}

\section{Research design and participants}

This study employed a descriptive-correlational, cross-sectional research design. The population of the study included all senior/fourth-year students $(n=233)$ enrolled in the Bachelor of Science in Nursing program in one government and two private nursing schools in Iloilo City, Philippines. The entire population was taken as participants. Total sampling was used, and the response rate was $100 \%$.

\section{Research instrument and data collection}

The Needlestick Injuries Reporting Intention Scale (NIRIS) was used to gather the data. The NIRIS is a self-administered questionnaire developed by the researchers to measure nursing students' attitude, subjective norms, perceived behavioral control, and intended reporting behaviors regarding needlestick injuries as well as demographic characteristics, prevalence, and past experiences of reporting needlestick injuries. The NIRIS was patterned after Feng and Levine's (2005) and Feng and Wu's (2005) Child Abuse Report Intention Scale that was utilized by Atencion et al. (2019) within the Philippine setting. Intention to report needlestick injuries was defined as the degree of likelihood of reporting needlestick injuries. Nursing students intended behavior of reporting needlestick injuries was assessed using ten vignettes of hypothetical situations. It was measured using a 10point continuum from " $1=$ almost certainly would not report" to " $10=$ almost certainly would report". Attitude toward reporting needlestick injuries referred to the degree of positive or negative value placed on reporting needlestick injuries. It was measured using ten attitudinal statements with responses in a 6-point continuum of " $1=$ strongly disagree" to " $6=$ strongly agree". Subjective norm was defined as nursing students' perceptions of social pressure whether or not to report needlestick injuries. Students were asked to assess how likely it is that their classmates, clinical instructors, staff nurses, and hospital personnel would approve or disapprove their reporting behavior. It was determined using five items answerable in a 5-point Likert-type with responses ranging from " $1=$ definitely no" to " $5=$ definitely yes". Perceived behavioral control over reporting needlestick injuries was defined as the confidence, perceived ease, or difficulty of reporting needlestick injuries. Ten items were included that relate to nursing students' perception of the control they have in reporting needlestick injuries. Responses were on a 5-point Likert-type scale ranging from " $1=$ definitely no" to " $5=$ definitely yes". Higher scores suggest higher intention to report, a more positive attitude, subjective norms having a greater influence on nursing students, and greater control over reporting needlestick injuries.

The face and content validity of the NIRIS were evaluated by a panel of (5) five jurors: two clinical instructors/professors in the nursing field, two medical doctors, and one infection control nurse. Irrelevant and unclear items were removed during the validation process and were not included in the instrument's final form. The NIRIS was pilot tested 
with 30 nursing students in another nursing school not included in the actual survey. The Cronbach's alphas for the different parts of the scale ranged from 0.69 to 0.80 , indicating an acceptable internal consistency or reliability of the instrument.

Data were collected in September 2018 after administrative clearances were secured from the Colleges of Nursing deans. There were three nursing schools in Iloilo City that gave consent for researchers to conduct the study. The researchers approached the participants during the scheduled time given by the school to conduct the study. The researchers personally distributed the paper survey tool to the participants after receiving the signed informed consent forms. Instructions were provided on how to complete the questionnaire. It took about 5 to 15 minutes to fully fill out the survey.

\section{Statistical data analysis}

The data were entered in Microsoft Excel and were computed by IBM SPSS version 23. Descriptive statistics used include frequency, percentage, mean (M), and standard deviation (SD). Pearson's correlation coefficient was utilized to test for significant relationships between variables after the normality test suggested a normal distribution of data. A p-value equal to or less than 0.05 was considered statistically significant.

\section{Ethical considerations}

The technical and ethical soundness of the study were reviewed by the thesis committee of the college before the actual investigation. A signed consent form was obtained from all participants. No personal identifiers were collected to protect the anonymity of the participants and the confidentiality of the data.

\section{RESULTS}

\section{School and sex distribution of nursing students}

Table 1 presents the distribution of 233 fourth-year nursing students according to school and sex. The majority of the nursing students included in this study were females $(83.69 \%)$ and from a public or government-funded nursing school (68.67\%).

Table 1. School and sex distribution of nursing students $(n=233)$

\begin{tabular}{lcc}
\hline Characteristics & $f$ & $\%$ \\
\hline Nursing School & & \\
A (Public) & 160 & 68.67 \\
B (Private) & 54 & 23.18 \\
C (Private) & 19 & 8.15 \\
Gender & & \\
Female & 195 & 83.69 \\
Male & 38 & 16.31 \\
\hline
\end{tabular}

\section{Prevalence and history of reporting needlestick injuries}

Table 2 shows that out of 233 participants, 35 or $15 \%$ of nursing students had previously experienced a needlestick injury. Moreover, 19 of $35(54.29 \%)$ nursing students who suffered a needlestick injury did not report the incident, while 16 or $45.71 \%$ reported the injury to authorities. 
Table 2. Prevalence and history of reporting needlestick injuries

\begin{tabular}{lcc}
\hline Prevalence of needlestick injuries $(n=233)$ & $f$ & $\%$ \\
\hline Had experienced a needlestick injury & 35 & 15 \\
Had not experienced a needlestick injury & 198 & 85 \\
History of reporting needlestick injuries $(n=35)$ & & \\
Reported needlestick injury & 16 & 45.71 \\
Did not report needlestick injury & 19 & 54.29 \\
\hline
\end{tabular}

Nursing students' attitude, subjective norm, perceived behavioral control

As shown in Table 3, almost all $(98.7 \%)$ of nursing students had a positive attitude $(M=5.41 ; S D=0.63)$ toward reporting needlestick injuries. Nearly all $(98.3 \%)$ reported high social pressure $(M=4.65 ; S D=0.46)$ in reporting needlestick injuries, and almost all $(98.3 \%)$ had high perceived behavioral control $(M=4.19 ; S D=0.45)$ in reporting needlestick injuries.

Table 3 Attitude, subjective norm, perceived behavioral control

\begin{tabular}{lcc}
\hline Variables & $f$ & $\%$ \\
\hline Attitude $(M=5.41 ; S D=0.63)$ & & \\
$\quad$ Positive (3.51-6.00) & 230 & 98.7 \\
$\quad$ Negative (1.00-3.50) & 3 & 1.3 \\
Subjective Norm $(M=4.65 ; S D=0.46)$ & 229 & 98.3 \\
$\quad$ High (3.01-5.00) & 4 & 1.7 \\
$\quad$ Low (1.00-3.00) & & \\
Perceived Behavioral Control $(M=4.19 ; S D=0.45)$ & 229 & 98.3 \\
$\quad$ High (3.01-5.00) & 4 & 1.7 \\
$\quad$ Low (1.00-3.00) &
\end{tabular}

\section{Nursing students' intention to report needlestick injuries}

It can be gleaned in Table 4 that generally, nursing students had a high intention $(M=8.99$; $S D=1.15$ ) to report needlestick injuries. Additionally, nursing students had the highest intention of reporting when pierced by a needle of an HIV positive patient $(M=9.82$; $S D=0.77$ ) and had the least intention of reporting when punctured with a lancet when checking the capillary blood glucose $(M=7.87 ; S D=2.61)$.

Relationship of attitude, subjective norm, perceived behavioral control to intention The result of statistical analysis using Pearson's correlation as displayed in Table 5 revealed that there was a significant positive relationship between attitude $(r=0.347$, $p=0.000)$, subjective norm $(r=0.230, p=0.000)$, perceived behavioral control $(r=0.246$, $p=0.000)$, and intention to report needlestick injuries.

Table 4. Intention to report needlestick injuries 


\begin{tabular}{lcc}
\hline Intention to Report Needlestick Injuries & $M$ & $S D$ \\
\hline $\begin{array}{l}\text { Pierced by a needle accidentally while fixing the bedside table of a } \\
\text { patient positive from HIV. }\end{array}$ & 9.82 & 0.77 \\
$\begin{array}{l}\text { Injured by the stylet when about to dispose after the IV insertion of a } \\
\text { patient with MRSA (Methicillin-resistant Staphylococcus aureus). }\end{array}$ & 9.65 & 1.00 \\
$\begin{array}{l}\text { Wounded by the needle hidden underneath the linens of the patient } \\
\text { who is diagnosed with syphilis. }\end{array}$ & 9.63 & 1.12 \\
$\begin{array}{l}\text { Punctured while giving Streptomycin injection of a patient suffering } \\
\text { from Pulmonary Tuberculosis. }\end{array}$ & 9.34 & 1.43 \\
$\begin{array}{l}\text { Pricked by the needle after pulling out the side drip at the Y-port of a } \\
\text { patient who has malaria. }\end{array}$ & 9.26 & 1.70 \\
$\begin{array}{l}\text { Pierced by the tip of a needle of a pre-filled syringe while recapping. } \\
\text { Pricked by the needle of a syringe while inflating the balloon port of }\end{array}$ & 8.93 & 1.66 \\
$\begin{array}{l}\text { a newly inserted indwelling catheter. } \\
\text { Injured by the needle while preparing the patient's medications. }\end{array}$ & 8.69 & 2.09 \\
$\begin{array}{l}\text { Pierced by the needle before administering insulin to a patient. } \\
\text { Punctured finger with a lancet when about to test the patient's }\end{array}$ & 8.34 & 2.37 \\
$\begin{array}{l}\text { capillary blood glucose (CBG). } \\
\text { Composite score }\end{array}$ & 2.24 \\
\hline
\end{tabular}

Table 5. Correlation of variables

\begin{tabular}{lcc}
\hline Independent variables & $r$ & $p$ \\
\hline Attitude & 0.347 & 0.000 \\
Subjective norm & 0.230 & 0.000 \\
Perceived behavioral control & 0.246 & 0.000 \\
\hline
\end{tabular}

\section{DISCUSSION}

This study explored the factors affecting the intention to report needlestick injuries among nursing students. It is noteworthy that nursing students in this study had high intention to report needlestick injuries. Moreover, the variables in the Theory of Planned Behavior: attitude, subjective norm, and perceived behavioral control were found to be significantly correlated with intention to report needlestick injuries. Nursing students are more likely to report cases of needlestick injuries if they are more affirmative on reporting the injury, they are confident that their classmates, clinical instructors, staff nurses, and hospital personnel support their reporting behavior, and they are fully in control in reporting needlestick injuries. The finding of this study affirms prior researches applying the Theory of Planned Behavior identifying factors associated with behavioral intentions of nursing students and nurses. The constructs of attitude, subjective norm, and perceived behavioral control influenced the behavioral intention of nursing students to report medication errors (Natan et al., 2017) and of nurses to report child abuse (Atencion et al., 2019; Feng \& Wu, 2005). Other prior researches also partially supported the Theory of Planned Behavior. For instance, nurses' intention to report adverse events (Ekayani et al., 2017) and child abuse (Cho \& Kim, 2016) were influenced by attitude and perceived behavioral control.

This study also demonstrated that while $85 \%$ of the participants had not experienced needlestick injury, $15 \%$ of the sampled nursing students had experienced needlestick injuries during their course. This result is comparable among Australian nursing students, 
wherein $13.9 \%$ reported a needlestick or sharps injury during the previous 12 months, and among nursing students in Hongkong, wherein the annual prevalence of needlestick injuries was 0.6 to 1.6 cases. However, much higher rates were reported with nursing students in India (91.85\%) and Taiwan (56.00\%) (Handiyani et al., 2018), China (60.3\%) (Zhang et al., 2018), Turkey (33.0\%) (Ozer \& Bektas, 2012), and among Arab nursing students in Jordan, Egypt, Iraq and Saudi Arabia (40\%) (Nawafleh et al., 2019). Nonetheless, regardless of the number of needlestick injuries, the incident requires attention because of the risk of exposure to blood-borne pathogens to students. A study in Hong Kong disclosed that 58.14\% of needlestick injuries were from contaminated needles (Cheung, Ho, Ching, \& Chang, 2010). Possessing adequate skills and competencies concerning procedures involving students to handle sharp devices is crucial for nursing students (Handiyani et al., 2018).

Furthermore, it is alarming to note that there seems to be an underreporting of needlestick injuries among nursing students in this current study. A low level of reporting of needlestick injuries was also noted among nursing students in the United States (Thomas, 2020) and China (Zhang et al., 2018). Similarly, there were many unreported cases of needlestick injuries among healthcare workers as per the report of the Centers for Disease Control and Prevention (Tayaben, 2015). Nursing students' reasons for not reporting included the item was unused, fear of getting in trouble, fear that the incident would affect their grade, and concern about being perceived as lacking clinical skill (Smith \& Leggat, 2005; Thomas, 2020).

It is also interesting to note that although the intention to report needlestick injuries was relatively high in all hypothetical situations, nursing students declared the highest intention to report needlestick injury from an HIV positive patient. It appears that students are more likely to report more severe cases of needlestick injury that involves patients with highly infectious diseases. This is particularly important because of the documented transmission of HIV through needlestick injuries (Higginson \& Parry, 2013; Pavithran et al., 2015).

The results of this study present an important issue that needs to be addressed both effectively and urgently, and the outcomes of this study have important implications for nursing educators and other interested parties. Nursing faculties must be not only proactive in identifying underperforming students early in the class (Oducado, 2019) but also be proactive in promoting the safety of students. It is thereby necessary for nursing schools to develop effective needlestick prevention and monitoring program (Handiyani et al., 2018). In addition, there is a need to bridge communication gaps to enhance the reporting of needlestick injuries (Thomas, 2020) and build a culture that fosters safe reporting of cases. At the same time, it is necessary and desirable for nursing students to adopt safer behaviors when handling syringes and other sharps (Silowati, Handiyani, \& Rachmi, 2019).

This study has limitations that warrant attention when interpreting and using the results. First, establishing a causal relationship between key variables may not be possible considering the cross-sectional research design of the study. Also, representativeness cannot be guaranteed, and results cannot be widely generalized as first, second, and third- 
year levels were not part of this study, and nursing students in other parts of the country or internationally were excluded from the study. Additionally, data obtained for this study used self-report scales; response bias may be present. Also, although the NIRIS was subjected to validation and reliability testing prior to use, the psychometric property of the research instrument has not been subjected to a larger scale. There may be other factors that may influence the intention to report needlestick injuries; however, only the constructs of the Theory of Planned Behavior were included in the study. Further studies may be conducted to validate the present investigation.

\section{CONCLUSION}

Understanding factors associated with the intention to report needlestick injuries is vital in planning interventions that foster and cultivate error reporting. The results of this study validate the usefulness of the Theory of Planned Behavior in analyzing factors that may influence nursing students' intention to report needlestick injuries. The constructs of attitude, subjective norm, and perceived behavioral control significantly influence nursing students' intention to report needlestick injuries. Additionally, there seems to be underreporting of needlestick injuries among nursing students. Teaching students to adopt safer behaviors, bridging communication gaps, fostering a culture of safe reporting and monitoring system, and establishing an effective prevention program for needlestick injuries among nursing schools is thereby necessary.

\section{ACKNOWLEDGMENT}

The authors would like to thank the Deans of the schools where the study was conducted and the nursing students who participated in the study.

\section{CONFLICT OF INTEREST}

The authors declare no conflict of interest.

\section{REFERENCES}

AlDakhil, L., Yenugadhati, N., Al-Seraihi, O., \& Al-Zoughool, M. (2019). Prevalence and associated factors for needlestick and sharp injuries (NSIs) among dental assistants in Jeddah, Saudi Arabia. Environmental Health and Preventive Medicine, 24(1), 60. doi:10.1186/s12199-019-0815-7

Ajzen, I. (1991). The theory of planned behavior. Organizational Behavior and Human Decision Processes, 50(2), 179-211. doi:10.1016/0749-5978(91)90020-T

Atencion, B.C.S., Alingalan, A.F., Oducado, R.M.F., Cordova, J. D N., Dumaguing, M.C.M., \& Suaboksan, M.T.T. (2019). Factors associated with intention to report child abuse among district hospital nurses in Iloilo, Philippines. International Journal of Caring Sciences, 12(1), 210-217.

Cheung, K., Ho, S.C., Ching, S.S.Y., \& Chang, K.K.P. (2010). Analysis of needlestick injuries among nursing students in Hong Kong. Accident Analysis \& Prevention, 42(6), 1744-1750. doi:10.1016/j.aap.2010.04.015

Cho, K.M., \& Kim, E.J. (2016). Nursing students' knowledge, attitudes, perceived behavior control and intention to report cases of child abuse. Child Health Nursing Research, 22(2), 145-152. doi:10.4094/chnr.2016.22.2.145 
Ekayani, N.P., Wardhani, V., \& Rachmi, A.T. (2017). Nurses' intention and behavior in reporting adverse event: application of theory of planned behavior. Kesmas: National Public Health Journal, 11(3), 138-144. doi:10.21109/kesmas.v11i3.1091

Feng, J.Y., \& Levine, M. (2005). Factors associated with nurses' intention to report child abuse: A national survey of Taiwanese nurses. Child Abuse \& Neglect, 29(7), 783795. doi:10.1016/j.chiabu.2004.11.006

Feng, J.Y., \& Wu, Y.W.B. (2005). Nurses' intention to report child abuse in Taiwan: A test of the theory of planned behavior. Research in Nursing \& Health, 28(4), 337347. doi:10.1002/nur.20087

Gabriel, E. H., Hoch, M. C., \& Cramer, R. J. (2019). The development of the theory of planned behavior and health belief model scales: Assessing behavioral determinants of exercise-related injury prevention program participation. Athletic Training and Sports Health Care, 11(3), 113-123. doi:doi.org/10.3928/19425864-20180802-01

Hada, V., Saurabh, K., Sharma, A., Nag, V.L., Gadepalli, R.S., \& Maurya, A.K. (2018). Nursing students: A vulnerable healthcare worker for needlesticks injuries in teaching hospitals. Journal of Family Medicine and Primary Care, 7(4), 717-720. doi:10.4103/jfmpc.jfmpc_265_17

Hatefnia, E., Alizadeh, K., \& Ghorbani, M. (2019). Applying the theory of planned behavior to determine factors associated with physical activity by women with hypertension in rural areas of Iran. Asian Biomedicine, 12(2), 83-90. doi:10.1515/abm-2019-0005

Handiyani, H., Kurniawidjaja, L.M., Irawaty, D., \& Damayanti, R. (2018). The effective needle stick injury prevention strategies for nursing students in the clinical settings: A literature review. Enfermería Clínica, 28, 167-171. doi:10.1016/S11308621(18)30060-3

Higginson, R., \& Parry, A. (2013). Needlestick injuries and safety syringes: A review of the literature. British Journal of Nursing, 22 (Sup5), S4-S12. doi:10.12968/bjon.2013.22.Sup5.S4

King, K.C., \& Strony, R. (2020). Needlestick. StatPearls. Retrieved from https://www.ncbi.nlm.nih.gov/books/NBK493147/

Natan, M.B., Sharon, I., Mahajna, M., \& Mahajna, S. (2017). Factors affecting nursing students' intention to report medication errors: An application of the theory of planned behavior. Nurse Education Today, 58, 38-42. doi:10.1016/j.nedt.2017.07.017

Nawafleh, H.A., Abozead, S.E., Mohamed, F.R., Ahmed, A.M., \& Altaif, K.I., \& Muhbes, F.J. (2019). The incidence and circumstances of needle sticks injury (NSI) among Arab nurses students: Comparative study. Health Science Journal, 13(2). doi:1010.36648/1791-809X.1000649

Oducado, R.M.F. (2019). Are nursing students' early course and perceived performance related to their final and actual course performance?. Nurse Media Journal of Nursing, 9(2), 167-175. doi:10.14710/nmjn.v9i2.26675

Ozer, Z.C., \& Bektas, H.A. (2012). Needlestick injuries during education period in nursing students in Turkey. Procedia-Social and Behavioral Sciences, 46, 37983801. doi:10.1016/j.sbspro.2012.06.149

Padilla, R.R., Rogado, M.I., Tagalog, E., \& America, E. (2006). Needle stick injury: Philippine perspective. Philippine Journal of Nursing, 76(1), 3-6. 
Pavithran, V.K., Murali, R., Krishna, M., Shamala, A., Yalamalli, M., \& Kumar, A.V. (2015). Knowledge, attitude, and practice of needle stick and sharps injuries among dental professionals of Bangalore, India. Journal of International Society of Preventive \& Community Dentistry, 5(5), 406-412. doi:10.4103/2231-0762.165932

Quynh, A.T.T., \& Einhellig, K. (2017). Practices for prevention needlestick and sharps injuries among nursing students. Belitung Nursing Journal, 3(3), 183-190. doi:10.33546/bnj.63

Silowati, T., Handiyani, H., \& Rachmi, S.F. (2019). Prevention behavior for NSI among nursing students and nurses in Indonesia: A comparative study. Enfermería Clínica, 29 (Suppl 2), 803-807. doi:10.1016/j.enfcli.2019.04.120

Smith, D.R., \& Leggat, P.A. (2005). Needlestick and sharps injuries among nursing students. Journal of Advanced Nursing, 51(5), 449-455. doi:10.1111/j.13652648.2005.03526.x

Tayaben, J.L. (2015). Compliance with sharps injury prevention guideline among nurses in tertiary care hospitals in the Philippines. International Journal of Infection Control, 11(2), 1-8. doi:10.3396/ijic.v11i2.13172

Thomas, L.M.B. (2020). Underreporting of blood-borne pathogen exposures in nursing students. Nurse Educator, 45(2), 78-82. doi:10.1097/NNE.0000000000000696

Zhang, X., Chen, Y., Li, Y., Hu, J., Zhang, C., Li, Z., Stallones, L., \& Xiang, H. (2018). Needlestick and sharps injuries among nursing students in Nanjing, China. Workplace Health \& Safety, 66(6), 276-284. doi:10.1177/2165079917732799 